\title{
STEVENS-JOHNSON SYNDROME TREATED WITH CORTICOSTEROIDS
}

\author{
By J. H. Mitchell, M.B., Ch.B., D.Obst., R.C.O.G. \\ Senior House Officer, Glasgow Royal Infirmary; Lately Y.H.M.O., I.D. Hospital, Paisley
}

The Stevens-Johnson Syndrome, otherwise known as erythema multiforme exudativum, has lately become more widely recognised as being liable to present as an acute medical emergency. The case described here is of special interest for several reasons: it would seem to be the most severe example of the disease ever recorded, which did not end fatally; it was complicated by acute dysphagia necessitating treatment with intravenous fluids, by acute retention of urine, and by bilateral corneal ulceration which finally healed without scarring; and it responded well to treatment with steroid hormones, both systemic and topical.

\section{Case Report}

Mary X, a laundress, unmarried, aged 26 years, was admitted to hospital on 12th November, 1956.

\section{Present History}

Some three weeks previously she had consulted her general practitioner because of nausea, occasional vomiting, and intermittent colicky pain, radiating from the right iliac fossa upwards and retrosternally. The pain had no connection with meals, micturition or defaecation. There was no story of menstrual upset; her menses were usually heavy with a good deal of pain. She was diagnosed as suffering from nervous dyspepsia, and treated with aluminium hydroxide and phenobarbitone tablets; she took the latter for 14 days in a dose of $\frac{1}{4}$ gr. thrice daily. On roth November she became listless; her eyes were inflamed and itchy, her throat sore, and a frontal headache developed. She was notified to us as probably having an acute respiratory infection, more especially as there was an epidemic of acute laryngo-tracheo-bronchitis in the area at the time.

\section{Past History}

Measles, mumps and varicella in childhood. Menarche at I3 years of age. General health excellent. No known contact with any infectious disease ; no contact with dead birds or sick animals, or with the new detergents. No previous allergy of any kind.

\section{Clinical Findings on Admission}

The patient was a slim, listless girl, slightly drowsy, but not dyspnoeic; temperature $99.4^{\circ} \mathrm{F}$. pulse $96 / \mathrm{min}$., respirations $28 / \mathrm{min}$. She had $\dot{a}$ generalised mild, but itchy macular erythema on her face, trunk and limbs, but not on her scalp음 with additional facial oedema, and small ulcers onthe lips and buccal mucosa. Her eyes were swollert and red. The lung fields were clinically clear, the blood pressure $130 / 70 \mathrm{~mm}$. Hg., and the cardio $\overrightarrow{0}$ vascular system normal except for systolic mut murs at the mitral and pulmonic areas. In the abdomen there was localised direct tenderness afop slight guarding in the right iliac fossa and slighte left-sided subcostal tenderness. No masses weren palpable, and bowel sounds were normal. Pos $\frac{0}{\mathbb{D}}$ teriorly there was moderate tenderness of the spinal processes of the upper thoracic vertebraeo (especially $\mathrm{T}_{4}$ ), and slight tenderness in both loins Per rectum slight ballooning was noted, together with tenderness forwards and to the right.

\section{Immediate Investigations}

The urine was chemically and microscopically normal, and sterile on culture. Blood examination showed photohaemoglobin $14.4 \mathrm{G} / 100 \mathrm{ml}$., P.C.V 44 per cent., M.C.H.C. 32 g. per cent., white cellso $9,900 / \mathrm{cu}$. mm. (neutrophils 82 per cent., lympho cytes I I per cent., monocytes 7 per cent., eosino phils nil, basophils nil), films normal. Chese skiagram showed no abnormality.

\section{Diagnosis and Treatment}

It seemed that the picture of coryza with was most like the Stevens-Johnson Syndrome although atypical measles could not be entirelye excluded. As the patient was not dangerously il and seemed likely to have some abdominato surgical condition present as well, it was decided $\bar{b}$ not to use steroid hormones meantime. Treatmen $\mathbb{D}$ 


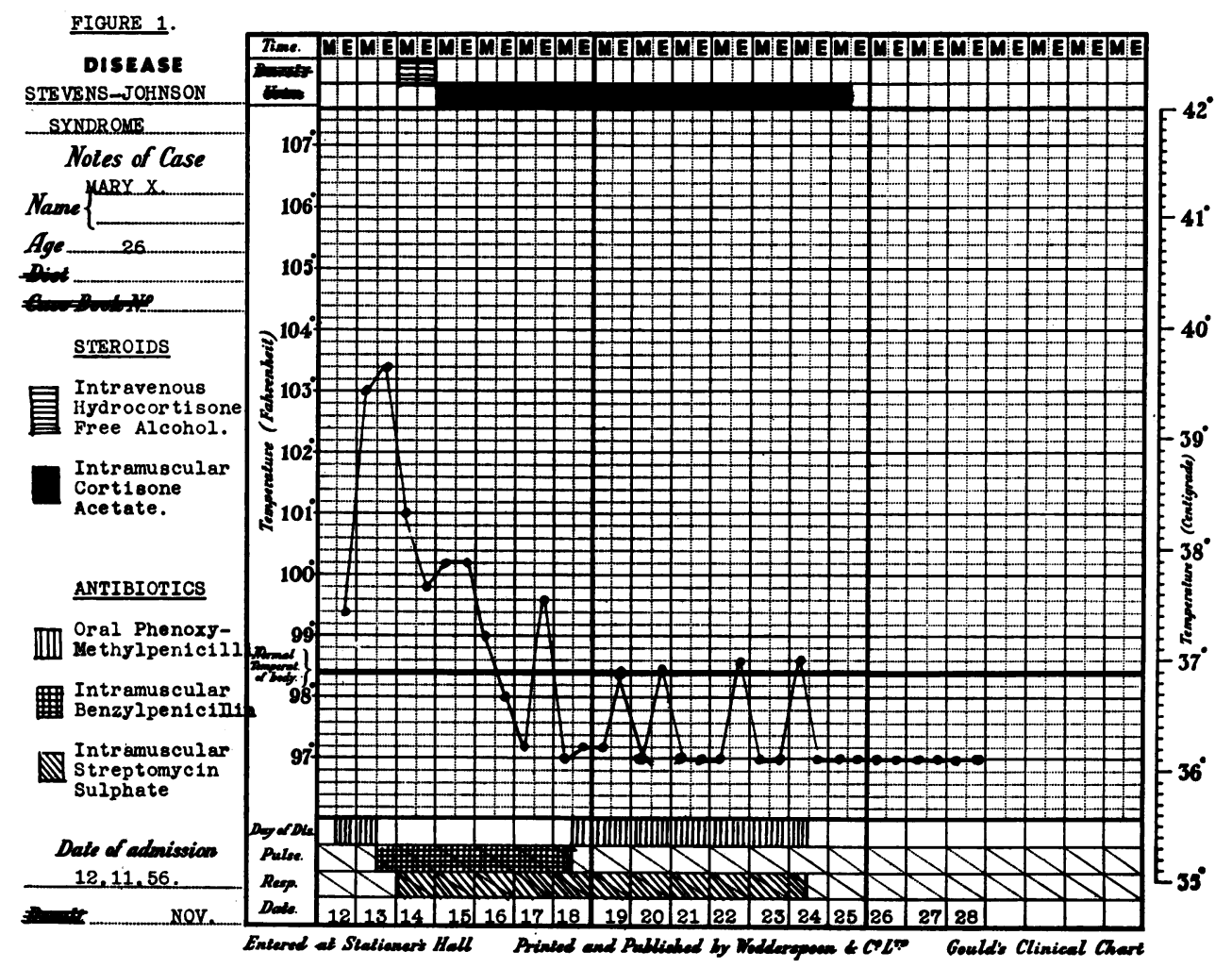

was started with oral diphenhydramine $150 \mathrm{mg}$. q.i.d.) and oral phenoxymethyl penicillin (250 mg. q.i.d.).

\section{Progress}

November I3. Patient drowsy; temperature I0 $3^{\circ} \mathrm{F}$; ; rash widespread and intense. Dysphagia and dysphonia apparent. Antibiotic changed to intramuscular benzylpenicillin $(500,000$ U.b.d.).

November 14. Condition much worse. Tongue ulcerated, swollen and dry; dysphagia complete; eyelids ulcerated and conjunctivae markedly reddened; micturition very painful. The abdominal symptoms and signs had nearly disappeared, and it was decided that treatment with steroid hormones and intravenous fluid was now imperative.

Accordingly, diphenhydramine was stopped, and a slow intravenous (stick-in) drip set up of 5 per cent. aqueous glucose; $75 \mathrm{mg}$. hydrocortisone free alcohol were administered in this medium during the next 8 hours, and thereafter cortisone acetate was given intramuscularly every 8 hours (see Fig. 2). Benzylpenicillin was continued intramuscularly and streptomycin sulphate (0.5. G. b.d.) begun by the same route. Sedation was provided by intravenous morphine in doses of I/ $12 \mathrm{gr}$.

Figure 2

Mary $X \quad$ Stevens-Fohnson Syndrome

DOSAGE OF STEROID HORMONES

A-HYDROCORTISONE-FREE ALCOHOL

\begin{tabular}{c|c|c}
\hline Date & Route & Total Dose \\
\hline I 4/I I & I.V. & $\begin{array}{c}75 \mathrm{mg} \text {. in } 750 \mathrm{ml} .5 \text { per cent. aqueous } \\
\text { glucose }\end{array}$ \\
\hline
\end{tabular}

B-Cortisone Acetate and Potassium Chloride

\begin{tabular}{|c|c|c|}
\hline Date & $\begin{array}{l}\text { Total Dose } \\
\text { I.M. Cortisone } \\
\text { Acetate }\end{array}$ & $\begin{array}{l}\text { Total Dose } \\
\text { Oral KCl }\end{array}$ \\
\hline $\begin{array}{l}15 / 11 \\
16 / 11 \\
17 / 11 \\
18 / 11 \\
19 / 11 \\
20 / 11 \\
21 / 11 \\
22 / 11 \\
23 / 11 \\
24 / 11 \\
25 / 11 \\
26 / 11\end{array}$ & $\begin{array}{l}300 \mathrm{mg} . \\
\text { 100 mg. } \\
\text { 1 } 00 \mathrm{mg} . \\
\text { 100 } \mathrm{mg} . \\
75 \mathrm{mg} . \\
50 \mathrm{mg} . \\
50 \mathrm{mg} . \\
50 \mathrm{mg} . \\
50 \mathrm{mg} . \\
37.5 \mathrm{mg} . \\
12.5 \mathrm{mg} . \\
-\end{array}$ & $\begin{array}{l}4 \text { g. } \\
4 \text { g. } \\
4 \text { g. } \\
4 \text { g. } \\
4 \text { g. } \\
4 \text { g. } \\
4 \text { g. } \\
4 \text { g. } \\
4 \text { g. } \\
4 \text { g. } \\
4 \text { g. } \\
2 \text { g. }\end{array}$ \\
\hline Total & $925 \mathrm{mg}$. & $46 \mathrm{~g}$. \\
\hline
\end{tabular}




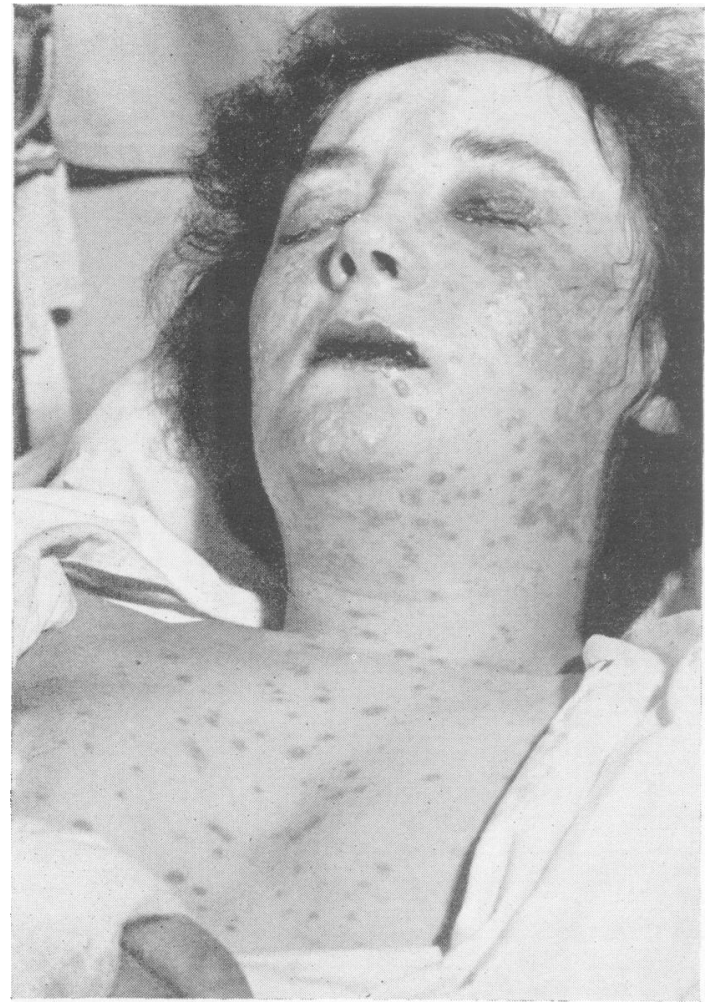

FIg. 3.-Patient's face, I 5/1 I/56.

November 15. Slight general improvement apparent, but dysphagia still severe, and acute retention of urine now present. Gross oedema of the vulva completely obliterated the normal contours of the labia majora and minora, and there was ulceration of the skin around the vaginal introitus. Catheterization was accomplished with great difficulty and $30 \mathrm{fl}$. oz. of clear urine obtained. Treatment continued with antibiotics and intramuscular cortisone acetate, and oral potassium chloride (in solution) begun in doses of $\mathrm{I}$ g. q.i.d., which the patient managed to swallow. Silicone cream applied routinely to all pressure points.

November I6. Dysphagia had decreased sufficiently for oral fluids to be taken without great difficulty, and the intravenous glucose was therefore stopped; altogether 7.5 pints had been given. Spontaneous voluntary micturition returned. The condition of the eyes began to give cause for anxiety. Until now they had been only moderately inflamed, and no local therapy had been given. However, this evening, the lids became rapidly oedematous and heavily crusted along the margins. Frequent swabbing with normal saline was started, and penicillin drops instilled. Elsewhere the skin eruption was getting no worse; on the face most of the original papules had progressed through the vesicular stage to crusting. On the trunk an limbs most of the lesions remained as papules slowly diminishing in size from about $\frac{1}{16}$ in. iro diameter, but becoming increasingly red. Pruritus had nearly disappeared. This evening, for the first time since admission, the temperature de creased to $98^{\circ} \mathrm{F}$.

November I7. Acute urinary retention recurreç which necessitated catherisation; vulval erosions was very marked. Fluids could be swallowed fairly easily, but not solids. Both eyes were fullyo closed by oedema, and sloughing of the lids was gross; tenderness was severe enough to preclude the possibility of proper examination except under $\vec{\omega}$ a general anaesthetic. She was taken to theatre $?$ anaesthetised with cyclopropane and oxygen, an examination and débridement carried out. Bothß corneae were found, on testing with fluorescein, to $\sigma_{+}$ be widely ulcerated. Local treatment was beguriw as follows: Saline swabbing of lids every 2 hours $\omega$ followed by the instillation of I per cent. hydrocortisone acetate drops and I per cent. chloram- + phenicol ointment, and the instillation of $x$ pers cent. atropine sulphate drops every 4 hours.

November 18 . Slow improvement maintained She could now sit up and speak faintly. Both eyes were partly open, with no crusting, vision being $\overrightarrow{0}$ of course, completely obscured by the local tregt-o ment. Anuria was still present, and catheter-0 ization again performed. This time vullat oedema had decreased sufficiently to make the location of the urethral meatus fairly easy. Keto-0 nuria was moderate. Penicillin therapy was changed back to phenoxymethyl penicillin orally $\overrightarrow{;}$ streptomycin dosage changed to I g. once daily.

November 19. Taking oral fluids well. Crusts separating from face and lips; eyes satisfactory. After a small saline enema voluntary micturition became established.

November 20. Further general improvement. Taking jelly by mouth.

November 22. Very miserable and tired, butô no signs of psychosis developing. This state $₹$ seemed due to her being continually disturbed foro treatment of some kind, and to the effect of pro- $\rightarrow$ longed starvation. Sedation with intramuscularo morphine ( $\frac{1}{6} \mathrm{gr}$.) and chloropromazine $(25 \mathrm{mg}$.) त being employed.

November 23. Irritable and obtuse. All seda- 0 tives stopped and deliberate bullying used to N induce her to take nourishment, including 'Complan' (Glaxo).

November 24. Marked improvement; now cooperative and more cheerful. Facial crusts clear- $\stackrel{?}{?}$ ing; diction restricted mainly by crusts on the lips. Vulval oedema minimal. Antibiotics stopped.

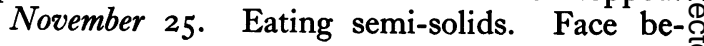


ginning to assume normal contours. Systemic cortisone therapy stopped. Corneal ulceration minimal; local treatment altered so that atropine henceforth applied only 12-hourly and hydrocortisone and chloramphenicol 4-hourly.

November 26. Pharyngitis with cervical lymphadenopathy. Her mouth could now open sufficiently to permit proper inspection; the mucosa of the cheeks, tongue, hard and soft palate, and uvula presented a crazy-paving or 'geographic' appearance with plaques of regenerating epithelium; I.25 Mega U. of fortified benethamine penicilllin (' Triplopen ': Glaxo) given intramuscularly. Potassium chloride stopped.

November 29. Left cornea completely healed. Treatment continued to both eyes as before.

December 2. Full diet taken for the first time. Attitude cheerful and co-operative; sleeping well. Skin of labia minora still slightly ulcerated, but no dysuria. Recrudescence of acute pharyngitis; I.25 Mega U. intramuscular 'Triplopen' again given.

December 3. Eye treatment altered as follows: 6 per cent. sulphacetamide drops applied to both eyes four times daily (but not at night) in place of the chloramphenicol ointment, hydrocortisone drops applied four times daily likewise, and atropine drops instilled 12-hourly as before. Allowed up in a chair.

December 7. Patient happy and laughing, but not euphoric; her starting to wear sunglasses to offset her photophobia enabled her cubicle, for the first time, to be unscreened to admit full daylight. All facial crusts had now separated; general desquamation continued over the rest of the body, with faint brownish staining. Hydrocortisone eye drops stopped, sulphacetamide continued, and atropine applied henceforth only once daily.

\section{December 9. Patient up walking about.}

December 14. Both cornae completely healed. All local eye treatment stopped.

December 22. Patient allowed home. Slight photophobia present; pupils not fully mobile. Scaling heavy on the soles of the feet, but only slight elsewhere. Five per cent. aqueous witch hazel was proving an excellent astringent to minimise any pruritus and tenderness of skin and nail roots. Facial appearance nearly normal, except for the total absence of eyelashes; pigmentation minimal, being mostly restricted to a faint malar redness. No trace remained of the original tenderness in her abdomen and back.

\section{Special Investigations}

The following were all done within a few days of admission and were all negative: Blood cultures, cultures from catheter specimens of urine, serum
Wasserman and Meinicke Reactions, serum Widal Reactions (B. Typhosus H. \& O., B. Paratyphosus A. H. \& O., B. Paratyphosus B. H. \& O., nonspecific salmonella, Brucella abortus and Brucella melitensis), and pregnancy tests for urinary chorionic gonadotrophins.

Serum potassium, sodium, chloride and urea estimations were made in case starvation plus the effect of steroid therapy should produce a biochemical imbalance, but values remained normal, and sarial readings of blood pressure were also all normal. It was noted that at the onset of hormone therapy the clotting time shortened to about I5 sec., but this effect lasted only for about two days.

Blood examinations on November 23, November 29 and December 20 showed red cell and white cell values within normal limits, and never an eosinophilia of more than I per cent.

Throat swabs taken at the attack of pharyngitis on November 26 were negative on culture for Strep. haem., B. diphtheriae and Vincent's organisms.

Chest skiagram on December I7 showed no abnormality. E.S.R. on December 18 was 28 $\mathrm{mm}$. (Westergren) in the first hour. Electrocardiogram on December 20 showed no abnormality.

During convalescence two serum specimens were tested for evidence of recent virus infection. Complement-fixation tests for the following were all negative:

Influenza soluble antigen (types A, B and C), newborn pneumonitis virus antigen, adenovirus group antigen, psittacosis-L.G.V. group antigen, and $Q$ fever ( $R$. burneti antigen).

\section{Further Progress}

When seen as an out-patient again on I4.I.57, Mary's general condition was excellent.

Skin. Rash completely healed in all areas. Minimal brown pigmentation in the malar areas, and slight telangiectatic mottling on the nose.

Nails: Shedding of nails progressing in both hands and feet. The old nails detached at the roots and new ones growing below them.

Abdomen. Occasional left hypochondriac pain, especially on laughing; and occasional mild retrosternal pain (heartburn). Rib cage mobile at left 9 th costal cartilage; pressure there reproduced this pain. Most suggestive of a slipping rib syndrome.

Eyes. Slight photophobia persisting. Pupils mobile. Lashes growing in well. Vision $6 / 6$ in each eye. No corneal scarring. Small adhesion at each inner canthus which will require resection.

Genito-urinary system. No dysuria. Menstruation not yet established. 


\section{Discussion}

The eponym Stevens-Johnson Syndrome dates from the original paper by Stevens and Johnson in 1922, but cases of a similar nature had been described previously in the Igth century; Rose nberg and Rosenberg (1940) mention a case recorded by Alibert and Bazin in 1822. However, most authorities give credit to von Hebra for the first description of the disease in 1860 . It was then known as erythema multiforme exudativum and consisted of skin erythema, ulceration at the orifices, and general constitutional upset. In I9I6, Reiter described a syndrome affecting German soldiers, and consisting of urethritis, conjunctivitis and arthritis. This is currently regarded as being closely related to the so-called non-bacterial or non-specific urethritis which has displaced gonorrhoea as the most prevalent venereal disease in U.K. Epstein (1947) compared Reiter's Disease with keratosis blenorrhagica and psorasis arthopathica, and Robinson and McCrumb (1950) reviewed a variety of cases of erythema multiforme exudativum previously described and regarded them as being all varieties of the so-called 'mucocutaneous syndrome.' The matter is still highly controversial and a wealth of literature exists dealing with the arguments. The Commission on Acute Respiratory Diseases (1946) declared that the Stevens-Johnson Syndrome was an eponym for which there was no justification.

Some writers consider von Hebra's cases to have been so mild that they would have an erythema multiforme exudativum (Hebra) described in contradistinction to the other acute erythema multiforme exudativum (Stevens-Johnson). Cooper (I955) considers the term 'muco-cutaneousocular syndrome' sufficient to include all cases of the von Hebra and Stevens-Johnson Syndromes and Reiter's Disease.

The diagnosis in the typical case of StevensJohnson Syndrome rests on the presence of ulcerative (or ' exudative') erythema multiforme, which may involve, besides the skin, the mucous membrane of the alimentary canal, the respiratory system, the genito-urinary tract, and the eyes. Haemorrhagic neuroretinitis (Cooper 1955) and meningitis (Todd 1953) have, on occasion, been described as features; pneumonia as shown by skiagram may be much more extensive than is thought from clinical findings (Cooper, I955). Shedding of nails is a fairly common sequel (Romer, 1953, and Humphrey, 1955). Dresner (1949) reported a case with ECG changes suggestive of pericarditis; joint effusions were also present.

Mauriello (1954) reviewed a series of 14 patients; four out of 13 were suspected initially of having aphthous ulcers and one of 10 with eye signs was seen by an ophthalmologist for one week before any other signs developed.

Ashby and Lazar (I95I) have conducted the most extensive review to date, comprising 81 cases The sex incidence was approximately $9: 2$ in favour of males; maximal incidence was in De-: cember, January and February, with a secondary rise in May. The skin of the scalp was alwayso free from lesions. Urethritis was common, buto retention (and then 'transient') was present in one⿳亠丷厂 case only. Conjunctivitis was present in $74 \stackrel{8}{\Omega}$ patients, being bilateral in all but four. Seveno had keratitis, and of these five went totally blind, one had residual scarring, and only one made a $\bar{\circ}$ complete recovery without scarring. The death rate in the 8I cases was eight, of which seven hado pneumonia present. The actual cause of deatho was non-specific: it has been attributed on occasions (Librach, I955) to circulatory collapse.

The etiology of the Stevens-Johnson Syndrome remains obscure. Some patients have recurrente attacks (Finland, r948). Numerous viruses havei been incriminated, e.g. vaccinia (Grant, I953), atypical pneumonia (Mauriello, 1954), psittacosis? (Finland, 1948) and mumps, foot and mouthdisease, and herpes simplex (Cooper, 1955), but most writers consider the condition to be a nonspecific allergic reaction, notwithstanding the façtẹ that even mild eosinophilia is seldom noted (\& cepting Goldfarb (1946), Finland (1948) a Vandermeer et al. (1953)) and that the " cubation period' is extremely variable. Foods, bacterial toxins, aspirin, barbiturates and sulphonamides are commonly mentioned (e.g. Cooper, I955), less commonly phenolphthalein $\underset{\vec{A}}{\vec{A}}$ (Mauriello, 1954), hydantoinates (Librach, I955), and phenylbutazone (Conway, I956) have been blamed. Barbiturates and sulphonamides are the two groups of drugs most commonly labelled as causative, and here again controversy arises, for 3 some authorities (Sommerville, I957) would consider my case to be one of barbiturate intoxication 3 . rather than the Stevens-Johnson Syndrome.

Treatment is no less controversial. Some authorities treat cases conservatively; others useo antihistamines, although no one has claimed that they are of much use. Jones (I95I) treated threeo cases with chlortracycline, and in one of them, being used as his own control, relapse occurred $\%$ with a placebo; Grant (I953) recorded an im-N mediate response to chloramphenicol; whilst the N్ల Lancet (I95I) in an editorial on the subject pointed out the considerable risk of inducing moniliasis by broad-spectrum antibiotic therapy.

Lately, steroid hormones have been more widely used. Librach (1955) considers they are good if employed early enough, and Fishman (I95I) hasō used them topically on skin lesions. Corticotro- 
phin is variable in response (Campbell 1955), perhaps due to variations in the potency of different preparations, and perhaps due to the adrenals not responding to stimulation because of toxic depression. There seems to be no record to date of intravenous hydrocortisone or topical hydrocrotisone having been used to arrest the progress of an acute case of the disease.

The severest case previously recorded in the literature appears to be that of Dresner (1949) already mentioned. Dysphagia was severe, but never sufficient to prevent oral fluids being taken; melaena was marked. There was no corneal ulceration, but retinal haemorrhages were present. In spite of severe proteinuria and dysuria, acute urinary retention did not occur. Rectal saline was administered early and blood transfusion employed later.

My own patient, Mary, was more critically ill, in the early stages, than any case I have seen recorded, but for reasons different from Dresner's patient. Her acute dysphagia made intravenous nourishment a necessity, which is in itself a difficult problem without being complicated by cortisone therapy and urinary retention. The latter, indeed, seemed at one stage as if it would require suprapubic cystostomy to relieve it, because the external genitalia were swollen and ulcerated almost beyond recognition. The employment of continuous drainage by indwelling urethral catheter was thought inadvisable in view of the risk of producing pressure necrosis of the mucosa. In addition to all this she developed a fulminating bilateral keratitis. In retrospect, there seems no doubt that Mary owes her life and her vision to corticosteroid therapy; it was quite remarkable how quickly she began to improve after the intravenous hydrocortisone, and how quickly the ocular oedema and exudation subsided during treatment with hydrocortisone drops.

Probably had bolder use of intravenous hydrocortisone been made, clinical response would have been more dramatic. A total of $75 \mathrm{mg}$. was given in about eight hours; $200 \mathrm{mg}$. in eight hours is recommended by some writers (Pfizer, I956). Mary's chest X-ray was clear, but the possibility of an intra-abdominal lesion being present, such as peptic ulcer, which had caused her original symptoms, was a constant worry, and even although she now presents with symptoms and signs suggestive of a left slipping rib, her original vomitting and epigastric pain remain unexplained.

In the presence of acute dysphagia the only alternative to intravenous hydrocortisone was an intramuscular preparation. Absorption here is slow compared to the oral route and may take from three to six days for one dose (Cope, 1956); accordingly, Mary was kept on the intramuscular preparation even after she could swallow, tof avoid the possibility of marked fluctuations in the blood hydrocortisone level. One need be less concerned about the gradual cessation of steroico administration by the intramuscular route than bye the oral route because of the depot effect already mentioned (Cope, 1956).

It has been assumed that Mary's condition was due to allergy to phenobarbitone. Now that she has recovered, the obvious way to prove thiş hypothesis would be to administer oral phenolo barbitone again in small doses to see if her cono dition recurred, but $I$ think that such a procedure would be quite indefensible in this particula? instance. Mary has therefore been told that she is highly allergic to all barbiturate preparations and that she is on no account to accept tablets or in 8 jections at any time without so informing the practitioner treating her.

As has been already noted, there was no past history of drug administration or contact with sick animals or dead birds, or of previous allergicis conditions.

Now that chemical analogues of cortisone are becoming more widely used, prednisolone would probably, by virtue of its lesser effect on serun electrolytes, be a more convenient drug to use in treating a similar case in the future.

\section{Summary}

A case is described of Stevens-Johnson Syn drome, featuring acute dysphagia, acute retention of urine and bilateral corneal ulceration.

It is suggested that this case may be the most severe example of the condition ever recorded.

The successful employment of steroid therapy? both parenteral and topical, is described in detail.

The clinical features and etiology of the Stevens Johnson and allied Syndromes are discussece. briefly.

It is suggested that prednisolone rather than cortisone or hydrocortisone would be more suit able for the treatment of similar cases in the future.

\section{Acknowledgements}

I am indebted to Dr. Wm. Napier, for per mission to publish this case; Dr. J. Boyd Adams Consultant Ophthalmologist, and Dr. Hugh Wishart, Consultant Anaesthetist, for help in the्E treatment; Dr. Paul Browning, Dr. Esthes McCulloch, Dr. R. G. Sommerville and Dr W. N. Weir, for the many laboratory investic gations; Mr. J. M. McCorquodale, for the photograph; and Miss Joyce Grant, for secretariato assistance.

Bibliography continued on page 392. 
An end-to-side bypass homograft was inserted from the aorta to the femoral artery, but shortly after releasing the clamp it was evident that thrombosis had occurred in the graft. Efforts to obtain a flow were unsuccessful and the graft was therefore removed.

He made a straightforward post-operative recovery and his symptoms were unaltered.

Case 2 (an R.A.F. flight-sergeant, age 46 )

This patient had noticed increasing weakness of the left leg for one year. He was unable to walk further than 150 yards because of this weakness, but had no actual pain. He recovered after resting for a short period and was able to walk a further I 50 yards.

On examination the colour and nutrition of the left leg were good and there was no obvious wasting. All pulses were present in this leg, but they were very weak. The pulses in the right leg were of normal volume. His blood pressure was $120 / 80 \mathrm{~mm}$. There were no other abnormalities on physical examination or laboratory investigation.

An aortogram performed at the R.A.F. Hospital, Ely, showed normal appearances except for an abnormally narrow but smooth external iliac artery.

At laparotomy the aorta, right iliac and left common iliac vessels were of normal calibre, soft and thin-walled with no evidence of atheroma. The left external iliac artery was extremely small, but also soft and thin-walled. The internal iliac artery was present, but also small.

An end-to-side bypass homograft was inserted from the common iliac to the femoral artery, which was normal in every way, the graft being passed under the inguinal ligament. After completing the anastomosis the clamps at both ends of the external iliac were not removed until a good flow had been established through the graft for some minutes. It was thought that this measure might reduce the likelihood of clotting in the graft.

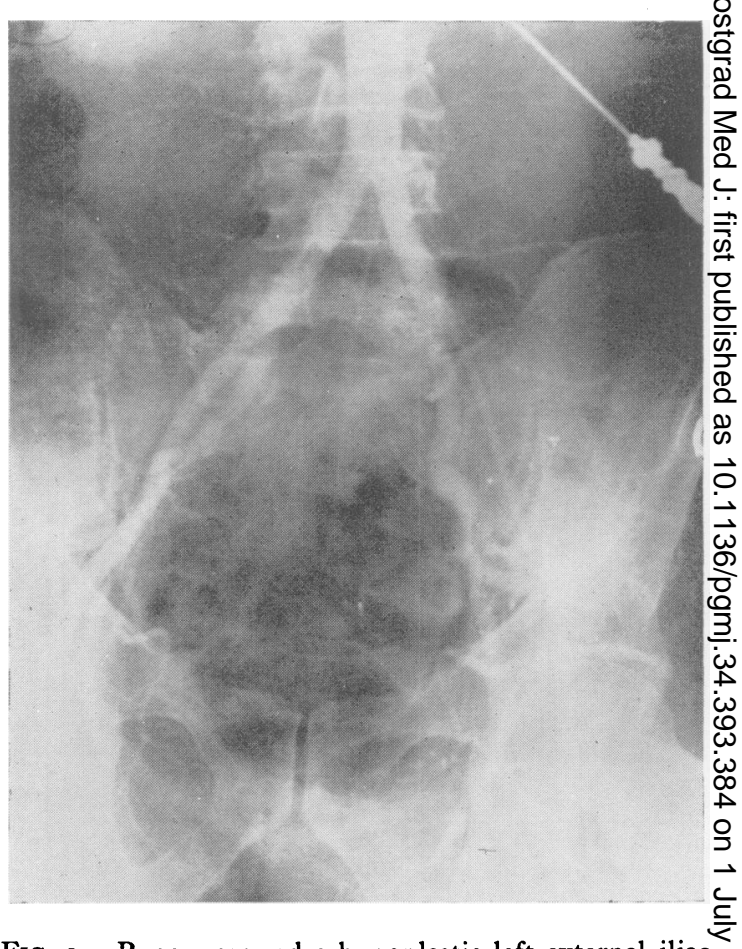

FIG. 2.-Bypass around a hypoplastic left external iliac artery (case No. 2).

Post-operatively he made a straightforwagd recovery and had full ankle pulses. An aortogra (Fig. 2) demonstrated the graft to be functioning well. The narrow external iliac vessel can also be seen in this picture.

When seen two months after operation he was able to walk an unlimited distance.

In both these patients the arteriographic appearances and the operation findings suggested that the iliac arteries were congenitally hypoplastic. It was not felt justifiable to remove a section of the 3 vessel for histology.

Bibliography continued from page 390-Y. H. Mitchell, M.B., Ch.B., D.Obst., R.C.O.G. BIBLIOGRAPHY

AGOSTAS, W. N., REEVES, N., SHANKS, E. D., and SYDENSTRICKER, V. P.'(r952), New Engl. F. Med., 246, 217.

ASHBY, D. W., and LAZAR, T. (1951), Lancet i, ro91.

CALDWELL, W. G. D. (1953), Lancet i, I 127.

CAMPBELL, C. H. (r955), Med. F. Austr. 26, 941 .

COARK, D. H. (1953), Lancet i, I255. (1946), Arch. intern. Med. 78, 687.

CONWAY, H. (1956), Personal communication.

COOPER, E. E. (1955), Tex. St. F. Med. 51, 6, 308.

COPE, C. L. (1956), Practitioner 175, 1049, 537.

DAVIES, D. M. (1953), Lancet i, 1126.

DRESNER, E. (1949), Lancet ii, 1036.

EPSTEIN (1947), Arch. Derm. Syph., 56, I91.

FINLAND, M. (1948), Amer. F. Med. 4, 473.

FISHMAN, H. C. (I95 I), Calif. Med. 74, 392.

GOLDFARB, A. A. (1946), $\mathcal{F}$. Pediat. 28, 579.

GRANT, P. W. (1953), Lancet i, 1129 .

Von HEBRA, F. (1860), 'Handbuch der Speziellen Pathologie,'

Von HEBRA, F. (1866), 'On Diseases of the Skin' (London).

HOWARD, J. E., \& PEDVIS, S. (1 948), Amer. F. Dis. Child. 75, 695

HUMPHREY, J. A. H. (1955), Brit. Med. F. i, I 32 I.

JONES, I. (I95I), Lancet i, 1280 .

Lancet (1951), ii, 532.

LIBRACH, I. M. (I955), Postgrad. med. F., 31, 361, 570.

MAURIELLO, D. A. (1954), Amer. F. Med., I56, I495.

PATZ, A. (I947), New Engl. '尹. Med. 236, 697. Hundred Years.'

Hundred Years.'
REITER, H. (I916), Dtsch. med.Wschr., 42, 1535.
ROBINSON, H. M., and McCRUMB, F. R. (1950), Arch. Derm. N Syph., 6r, 539.

ROMER, C. (1953), Brit. Med. F., i, 768.

ROSENBERG, L., and ROSENBERG̈, J. (1940), Arch. Derm. Syph.

41, 1066.

SEDDON, I. B. (1947), Brit, Med. F., i, 925.

SNEDDON, I. B. (1953), Lancet, i, 1255

SOMMERVILLE, J. (I957), Personal communication.

STEIGMAN, A. J., and KELLY, J. J. (I952), Lancet, i, 875.

THOMAS, B. A. (1950), Brit. Med. F., i, 1393.

TODD, R. M. (1953), Med. Illust., 7, 746.

(1953), New E'igl. F. Med., 248, 806. 